\title{
Lateral Behavior of Pile Foundations during Partial Liquefaction
}

\author{
Dammala P.K. ${ }^{1}$, Rouholamin, M. ${ }^{2}$, Nikitas G. ${ }^{3}$, Bhattacharya, S. ${ }^{4}$, Adapa, M.K. ${ }^{5}$ \\ ${ }^{1}$ Research Scholar, Department of Civil and Environmental Engineering, University of Surrey, \\ P.O. Box GU2 7XH, Guildford, United Kingdom; p.dammala@surrey.ac.uk \\ ${ }^{2}$ Teaching Fellow, Department of Civil and Environmental Engineering, University of \\ Portsmouth, P.O. Box PO1 AH, Portsmouth, United Kingdom; mehdi.rouholamin@ port.ac.uk \\ ${ }^{3}$ Research Scholar, Department of Civil and Environmental Engineering, University of Surrey, \\ P.O. Box GU2 7XH, Guildford, United Kingdom; g.nikitas@surrey.ac.uk \\ ${ }^{4}$ Chair Professor, Department of Civil and Environmental Engineering, University of Surrey, \\ P.O. Box GU2 7XH, Guildford, United Kingdom; s.bhattacharya@surrey.ac.uk \\ ${ }^{5}$ Associate Professor, Department of Civil Engineering, Indian Institute of Technology \\ Guwahati, P.O. Box 781 039, Guwahati, India; amurali@iitg.ernet.in
}

\begin{abstract}
Pile foundations in liquefiable soils need to be checked for the bending moments due to the liquefaction induced stresses to arrest the plastic hinge formation. Recent studies reveal that the bending moments in the pile are significantly higher during the partial liquefaction stage (excess pore water pressure ratio $<1.0$ ) than at the fully liquefied condition. This study proposes a method to estimate the pile bending moments during partial liquefaction. Advanced multi-stage cyclic triaxial tests are conducted on sandy soil to understand the partial liquefaction behavior. The test results are then utilized to model the soil pile interaction in partially liquefiable soils following the Beams on Nonlinear Winkler Foundation (BNWF) approach. The method is based on mobilized strength design concept. The developed numerical model is analyzed using the traditional lateral soil springs along with the proposed springs. It is understood from this study that the bending response of pile foundations in partially liquefiable soils can be effectively estimated with the proposed methodology compared to the existing models.
\end{abstract}

\section{INTRODUCTION}

Liquefaction is one of the challenging problems, geotechnical engineers often face during the earthquakes. Design engineers often suggest to use pile/caisson foundations in order to mitigate the adverse effects of liquefaction. However, even the pile foundations suffered serious damage during seismic liquefaction, see for example the collapsed Showa Bridge (1964 Niigata earthquake) reported by Bhattacharya et al., (2014), Magsaysay Bridge (1990 Philippines earthquake), and more recently failed Rokko Bridge and other pile supported structures (2011 
Tohoku earthquake). Research has improved significantly in the past 40-50 years in the subject of pile foundations and many failure mechanisms of pile foundations in liquefiable soils were unearthed. The safety of pile foundations against those mechanisms can be assured by arresting the plastic hinge formation in the pile during liquefaction (induced moments not exceeding the plastic moment capacity of the pile). This can only be achieved by effective estimation of the induced moments in the pile and reinforcing the pile with sufficient stiffness.

Figure 1 shows the schematic view of pile foundation in liquefiable soils and the traditional Beams on Nonlinear Winkler Foundation (BNWF) approach. The BNWF approach requires the soil-pile interaction to be modelled as P-Y springs (P-soil reaction, Y-pile displacement), see Figure 1 (b). Some standard codes of practice such as API (2007) provide guidelines to develop P-Y curves for sands and clays. In case of liquefiable soils, Dobry et al., (1995) and Brandenberg (2005) proposed a p-multiplier approach to scale the soil resistance for a liquefied soil depending on the relative density of the soil deposit. However, this approach lacks the basic representation of post liquefied behavior of soils-strain hardening with zero initial stiffness. More recently, Lombardi et al., (2016) proposed a bilinear Winkler spring approach considering the zero initial stiffness and strain stiffening behavior for liquefied soils, Figure 1 (d). It is important to note that the behavior of sandy soils during partial liquefaction $\left(0<R_{u}<1.0\right)$ is neither analogous to nonliquefied nor to fully liquefied conditions, and is therefore the application of any of the above approaches in estimating the bending response of piles in partial liquefaction can be questionable.

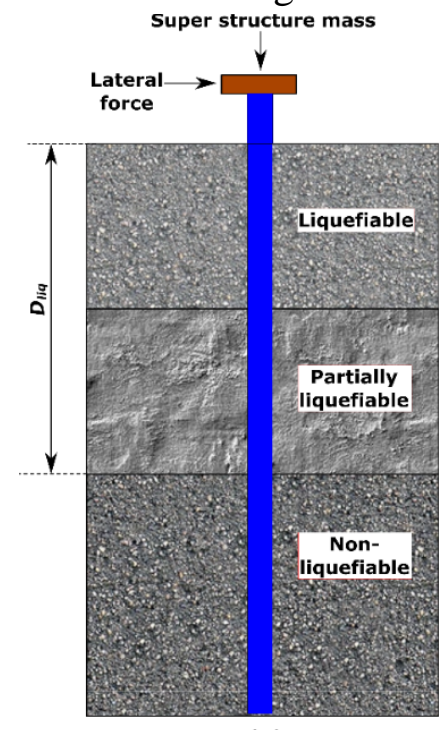

(a)

Actual pile soil

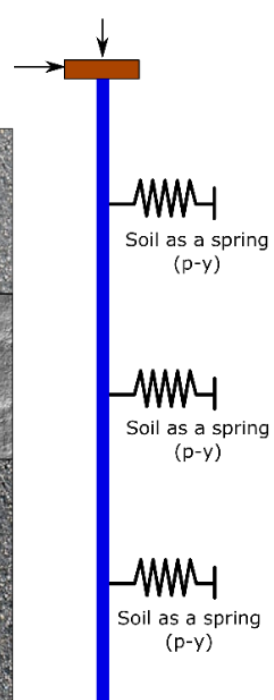

(b)

Idealized as BNWF model

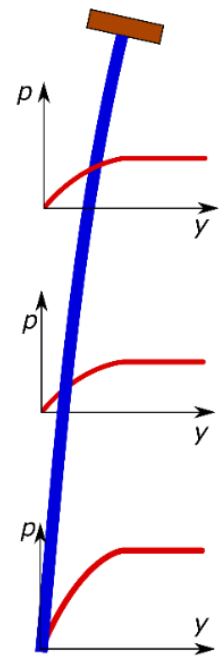

(c)

Standard p-y springs (API, 2000)

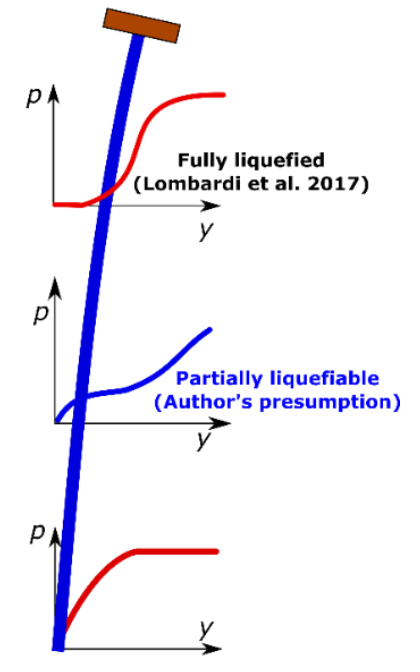

(d)

Liquefied, partially liquefied \& nonliquefied soil behavior

Figure 1. Schematic representation of modelling pile foundation in liquefiable soils

This paper presents a relatively better and technically sound approach in estimating the bending response of piles during partial liquefaction. Multi stage cyclic triaxial tests are conducted on sandy soil to understand the partial liquefaction behavior. The proposed method is based on scaled element test results and mobilized strength design concept proposed by Bouzid et al., 
(2013). The shake table test results of Rouholamin (2016) are considered for the calibration of the proposed method.

\section{SHAKE TABLE TESTS}

A series of shake table tests were conducted by Rouholamin (2016) on single and group of piles in a water tight container. Present study considers only the single pile, with a pile cap of $1.90 \mathrm{~kg}$ with a superstructure mass of $5.0 \mathrm{~kg}$. The pile is $2 \mathrm{~m}$ long, made of an aluminum pipe of external diameter $25.4 \mathrm{~mm}$ with a wall thickness of $0.711 \mathrm{~mm}$, embedded to a depth of $1.8 \mathrm{~m}$ in the homogeneous Redhill 110 sand. The pile is screwed at the bottom of the container to represent the fixity condition. Further details about the test setup can be found in Rouholamin (2016). The model is subjected to a scaled Christchurch earthquake motion of $0.63 \mathrm{~g}$ and the response of the soil (in terms of pore water pressure ratio, $R_{u}$ ), and the pile (bending moments along the depth) are shown in Figure 2 (a). A transition phase (termed as transient hereafter) can be observed during the liquefaction phase (rise in pore water pressures), where the bending moments of the pile changes significantly.
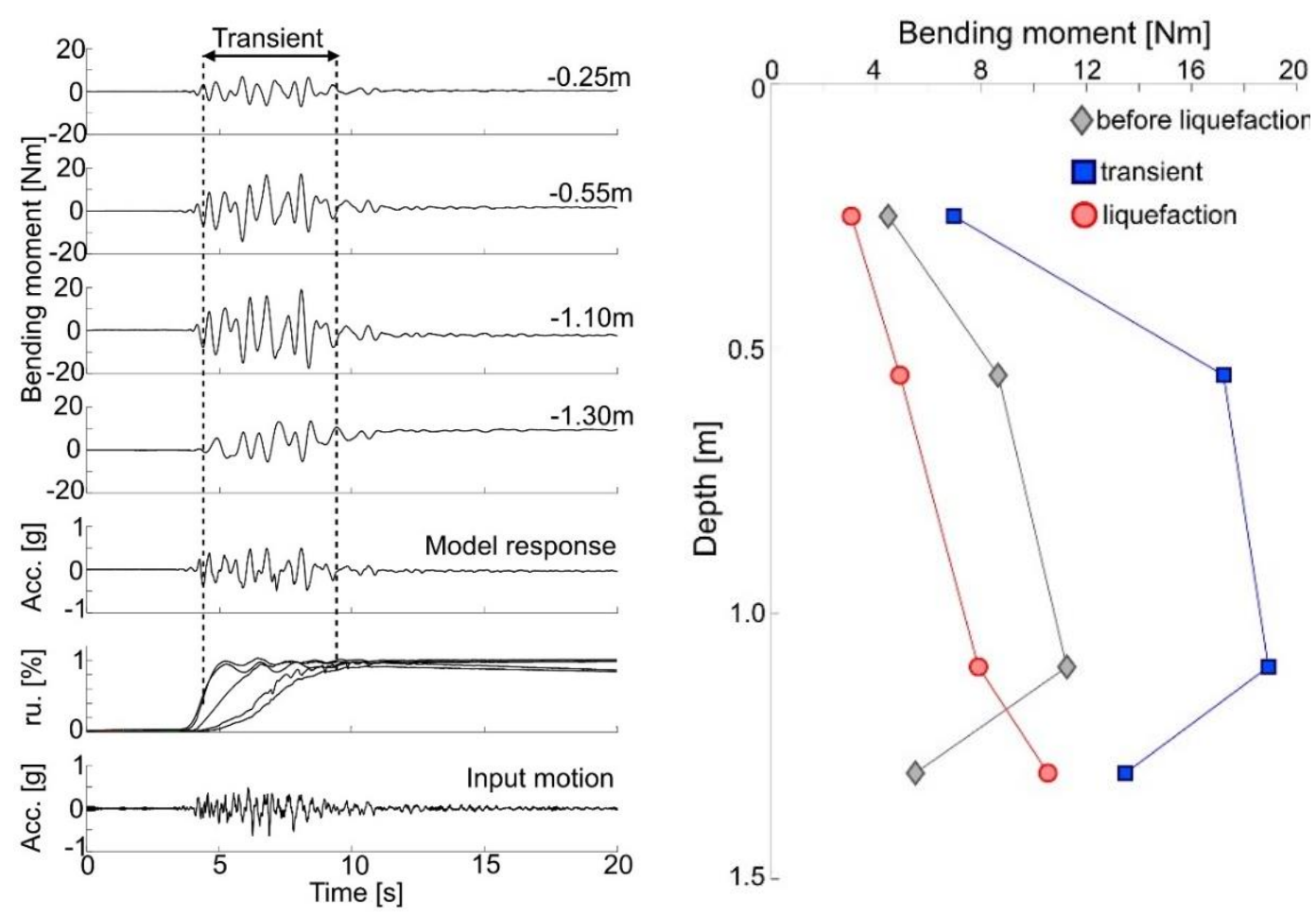

Figure 2. (a) Bending response of pile for Christchurch earthquake as input motion and the (b) Peak bending moment profile along the depth (Rouholamin, 2016)

It is interesting to note that the pile experienced peak bending moments (BM) during the transient phase contradictory to the traditional assumption of peak BM formation in fully liquefied conditions. The peak BM along the depth at different liquefaction levels is shown in Figure 2 (b). As described in the earlier section, scientifically established approaches are available to model 
either the non-liquefied or fully liquefied conditions. Therefore, using the shake table results of single pile, present study proposes an approach in estimating the bending response of pile foundations during partial liquefaction.

\section{LABORATORY ELEMENT TESTS}

The sand used in the shake table experiments (Redhill 110) is characterized. Index properties of the sand are presented in Table 1. The particle size distribution curve of the sand when compared with the liquefiable soil zones (Figure 3) suggested by MoT (1999) reveals that the soil is highly prone to liquefaction.

Table 1. Index properties of Redhill 110 sand

\begin{tabular}{cccccc}
\hline $\boldsymbol{G}_{\boldsymbol{s}}$ & $\boldsymbol{e}_{\min }$ & $\boldsymbol{e}_{\max }$ & $\boldsymbol{D}_{\boldsymbol{5 0}}(\mathbf{m m})$ & $\boldsymbol{C}_{\boldsymbol{u}}$ & Shape \\
\hline 2.65 & 0.608 & 1.035 & 0.13 & 1.63 & Angular \\
\hline
\end{tabular}

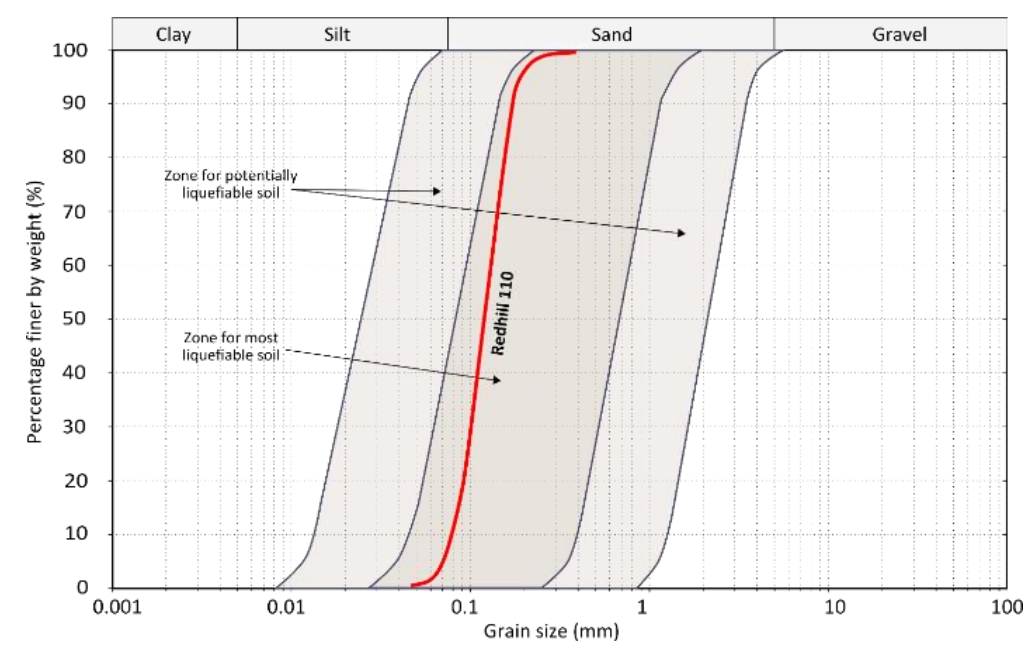

Figure 3. Particle size distribution of Redhill 110 sand compared the liquefiable soil zones

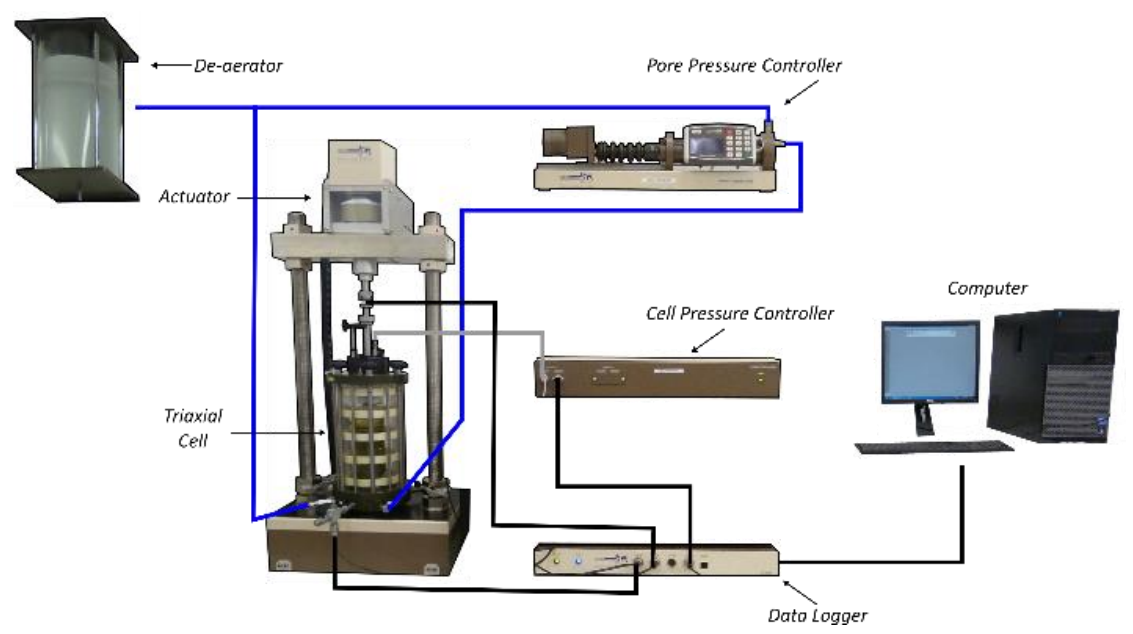

Figure 4. Schematic of the CTX apparatus used for element testing 
Cyclic Triaxial (CTX) Testing. Multi stage Cyclic Triaxial (CTX) tests are performed on Redhill 110 sand samples to understand the behavior of partially liquefied soils. The CTX apparatus available at SAGE lab, University of Surrey, UK has been utilized for the testing (Figure 4). Sample preparation is similar to the approach detailed in Rouholamin et al. (2017).

Test Program. Once the soil samples are saturated for an approximate B value of 0.95 , tests are performed in multi-stages. The first stage involves the isotropic consolidation of the sample to the required mean effective confining stress $\left(\sigma_{m}^{\prime}\right)$, the second stage engage with the cyclic loading of the sample to the required degree of liquefaction (excess pore pressures are monitored during the cyclic loading) and the third stage consists of strain controlled monotonic loading to check the effect of liquefaction levels on the post (partial/full) liquefaction behavior. Table 2 list the tests performed and their loading conditions. Figure 5 describes the testing method for partial liquefaction in which the $\sigma_{m}^{\prime}$ is allowed to reduce depending on the required level of partial liquefaction $\left(R_{u}\right)$. Tests at three $R_{u}$ levels $(0.25,0.50$ and 0.75$)$ at $\sigma^{\prime}{ }_{m}$ of $100 \mathrm{kPa}$ and approximately $50 \%$ relative density, are performed along with the only monotonic (no liquefaction) and full liquefaction $\left(R_{u}=1.0\right)$ tests. Tests with $R_{u}$ levels $(0.25,0.50$ and 0.75$)$ are repeated to check the consistency of the results and found to be satisfactory.

Table 2. List of CTX tests performed on Redhill 110 sand

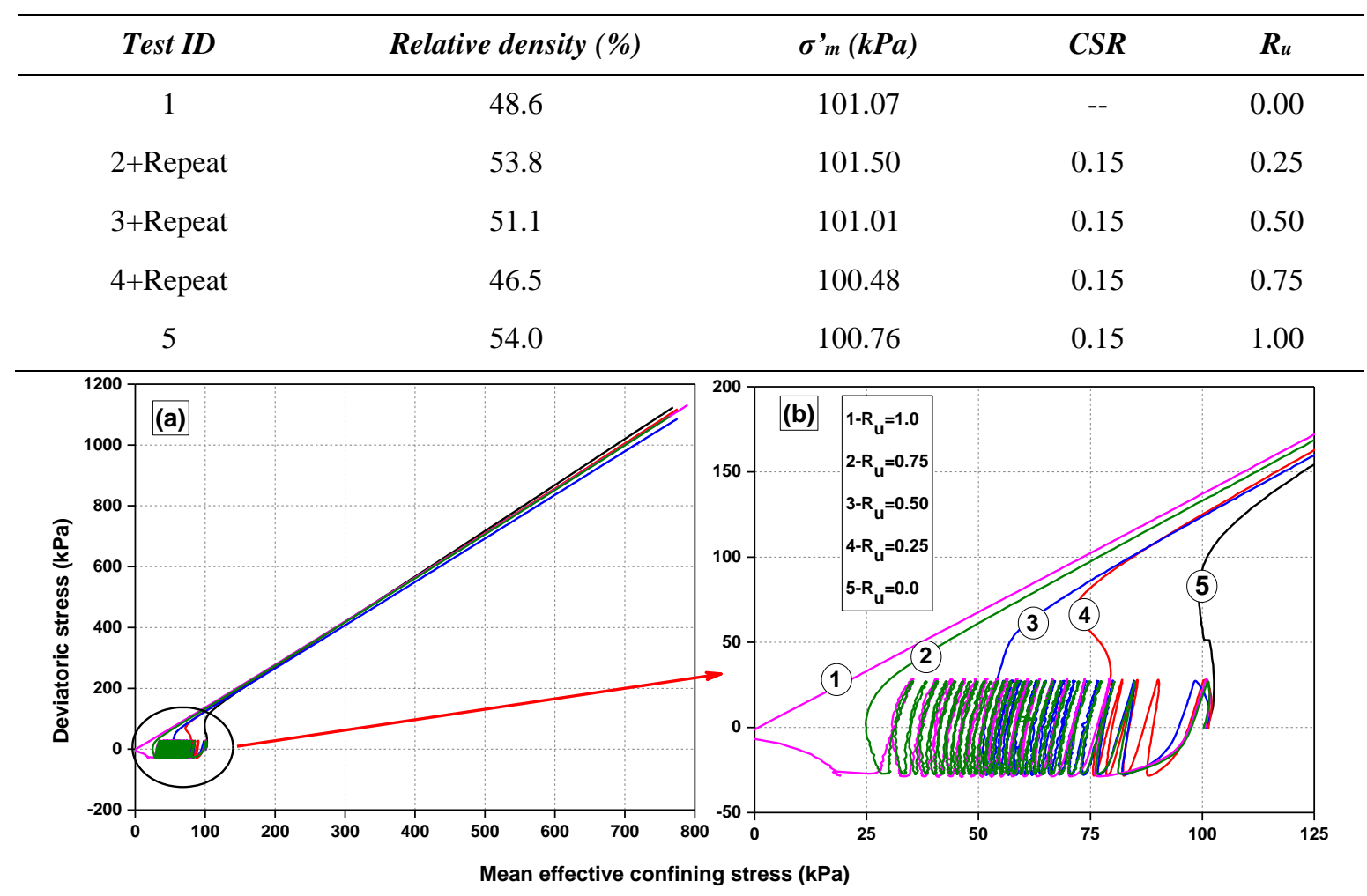

Figure 5. (a) Variation of deviatoric stress with mean effective stress for various liquefaction levels (b) enlarged view 
Test Results. Figure 6 presents the post partially/fully liquefied behavior in terms of deviatoric stress and axial strain for all the cases. It can be observed that the initial stiffness $\left(K_{\text {initial }}\right)$ of the soil reduced with increase in the level of liquefaction and for the fully liquefied sample, almost no initial stiffness is observed which is supported by the findings of Lombardi et al. (2014) and Rouholamin et al. (2017). It is quite interesting to note that the $K_{\text {initial }}$ for both the cases $\left(R_{u}=0.25\right.$ $\& 0.50)$ is analogous to the monotonic behavior, while the $75 \%$ liquefied sample has lost $K_{\text {initial }}$ the exhibiting the similarity of fully liquefied behavior. This suggests that there might exists a threshold liquefaction level where the $K_{\text {initial }}$ could be completely lost. Further description of this topic will need proper scientific backing with numerous test results and is beyond the scope of the present article.

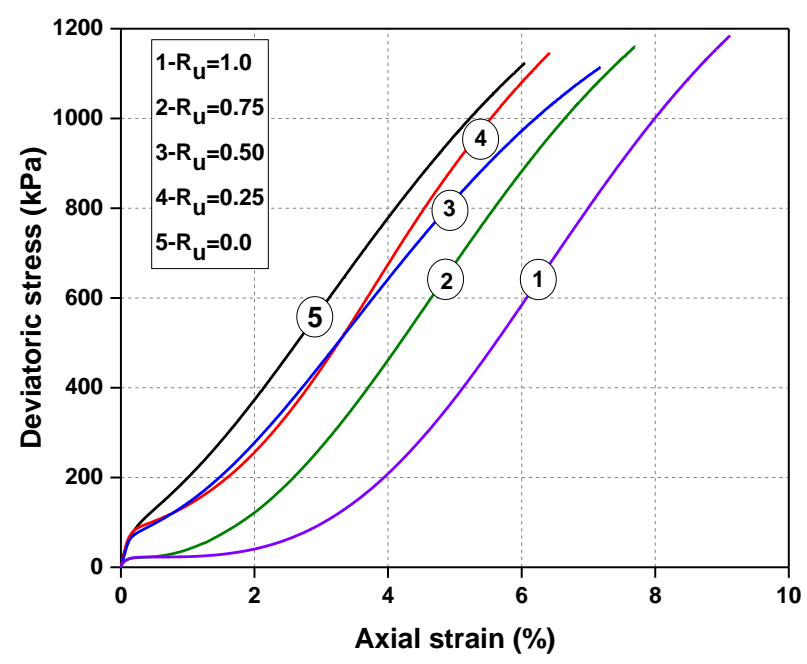

Figure 6. Variation of deviatoric stress to the post liquefaction axial strain for various levels of partial liquefaction

\section{DEVELOPMENT OF P-Y CURVES FOR PARTIALLY LIQUEFIABLE SOILS}

The obtained post partially liquefied stress-strain behavior of the sand samples from the element testing is then converted to the P-Y curves using the mobilized strength design concept proposed by Bouzid et al. (2013).

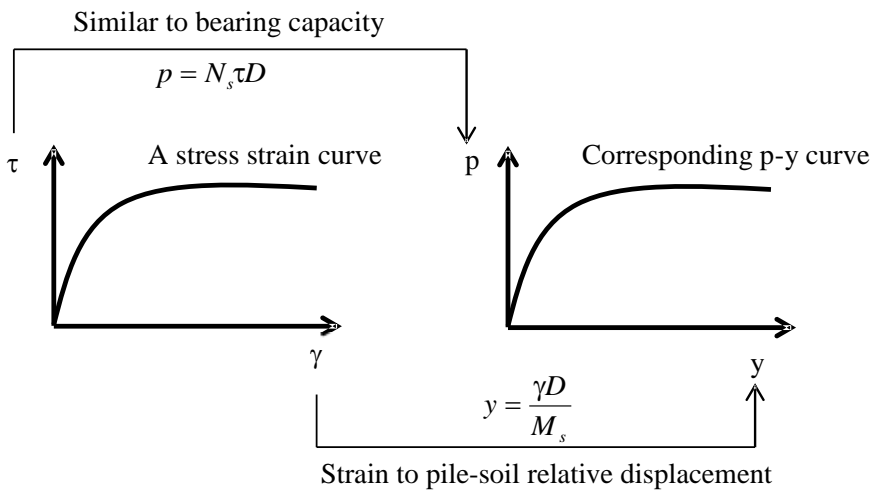

Figure 7. Scaling of stress-strain to P-Y (Bouzid et al. 2013) 
In this approach, the deviatoric stress variation with axial strain is first converted to shear stress-shear strain using the poison ratio and then scaled using the stress-strain scaling coefficients $\left(M_{c} \& N_{c}\right.$ respectively) to achieve the required P-Y curves, see Figure 7 for details. The element tests are conducted at $\sigma_{m}^{\prime}$ of $100 \mathrm{kPa}$ and the obtained P-Y curves are linearly scaled using the ratio of $\sigma^{\prime} m / P_{\text {atm }}$, where $P_{\text {atm }}$ represents the atmospheric pressure. The resulting P-Y curves at $25 \%$ and 50\% liquefaction are shown in Figure 8. The traditional P-Y curves were also developed based on three approaches, API (2007), p-mulitplier of 0.33 based on Brandenberg (2005) and fully liquefied condition based on Lombardi et al., (2016). All the P-Y curves developed along with the proposed partially liquefied curves are shown in Figure 8.

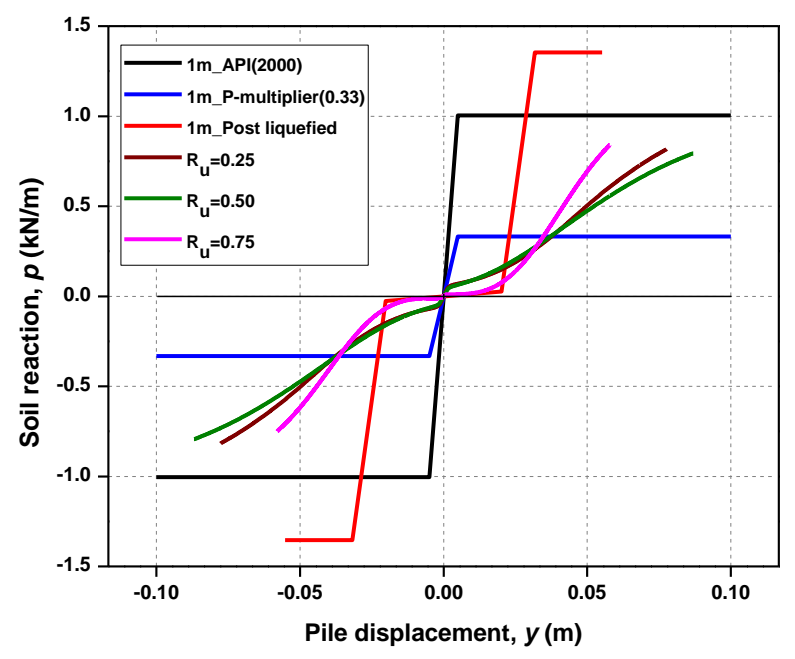

Figure 8. Comparison of the developed curves with the traditional p-y curves

\section{NUMERICAL MODEL}

The single pile is modelled using the BNWF approach using the finite element programme SAP2000 inorder to validate the shake table test results. The pile is modelled as a frame element with the properties considered from Rouholamin (2016). Soil is modelled as multi-linear elastic spring element along the depth of the pile with $5 \mathrm{~cm}$ spacing in between. Pseudo-static analysis is performed with two cases: one with the $25 \%$ liquefaction and other with $50 \%$ liquefaction. The required lateral load to be applied at the pile head is calculated based on the shake table results (Figure 2a). For $R_{u}=0.25$, input Peak Ground Acceleration (PGA) counts to $0.3 \mathrm{~g}$ resulting in a pseudo static lateral force of $2.07 \mathrm{~kg}$ while for $R_{u}=0.50$, PGA of $0.60 \mathrm{~g}$ is recorded leading to a lateral force of $4.14 \mathrm{~kg}$. Similarly, the model is also analyzed using the traditional P-Y shown in Figure 8 to check if any of the approaches can catch the bending response during partial liquefaction. It is important to note that the axial load (from the superstrucutre and pile cap) is present during the excitation in shake table and is also considered in the numerical model. In addition, the $P-\Delta$ effect is also considered during the loading.

\section{RESULTS \& DISCUSSION}


Figure 9 (a), (b) and (c) present the bending response of the single pile with the soil pile interaction modelled using the API (2000), P-multiplier and post liquefaction bilinear model by Lombardi et al., (2016) respectively, at different pseudo-static loading conditions.

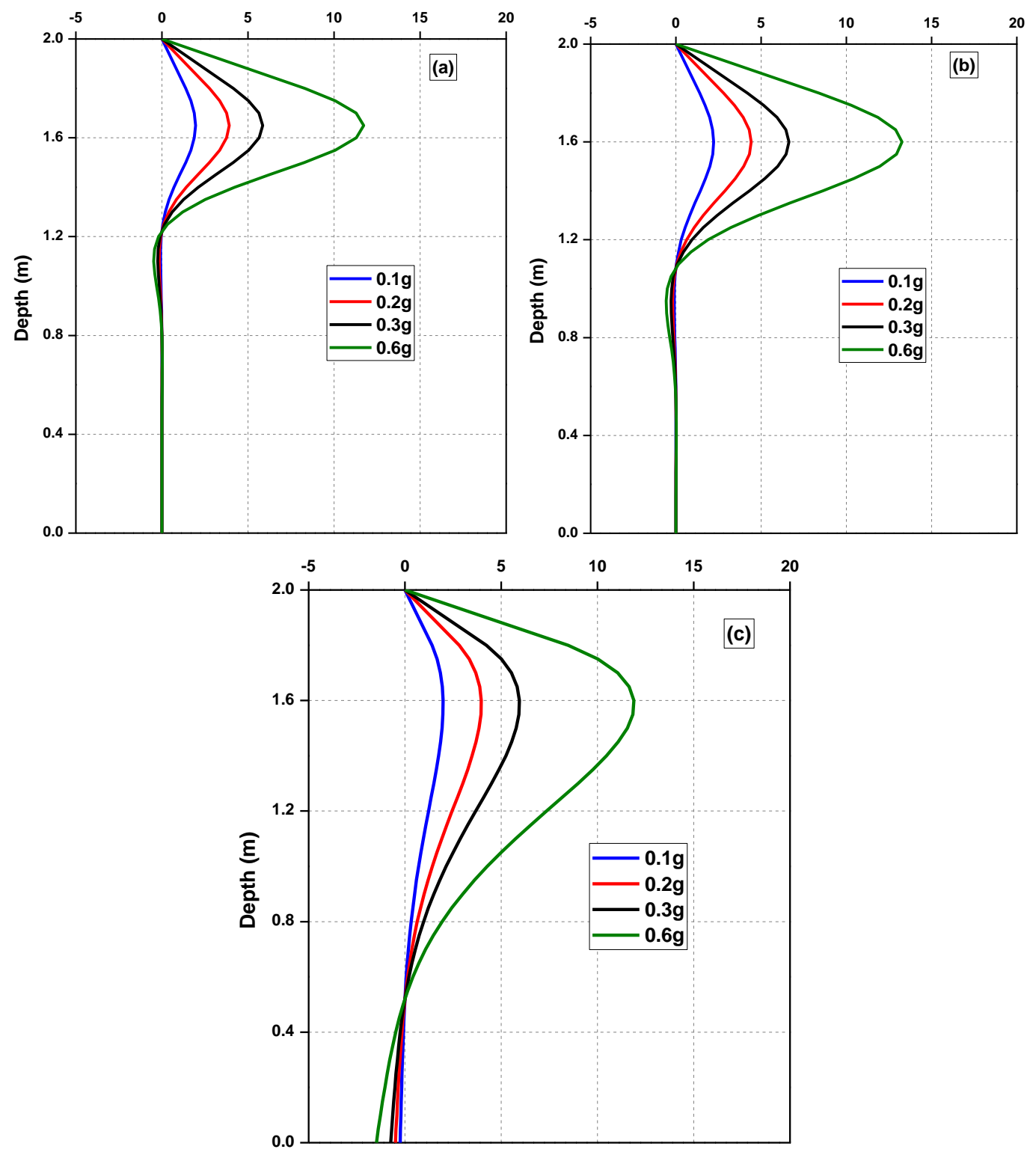

Figure 9. Bending response of pile using (a) API (2000) (b) P-multiplier (c) Post liquefaction bilinear model by Lombardi et al. (2016)

It is interesting to that the API (2000) and P-multiplier (Brandenberg, 2005) approaches yield similar peak BM pattern along the depth of the pile. However, the bilinear model proposed by Lombardi et al. (2016) predicted a fixed moment at the bottom unlike the other two approaches along with the zero BM being shifted to much deeper elevation (1.5 m from surface) due to the zero initial stiffness of the model. Figure 10 compares the peak BM profile along the depth for $25 \%$ and $50 \%$ liquefaction levels along with the traditional approaches with the shake table results. 

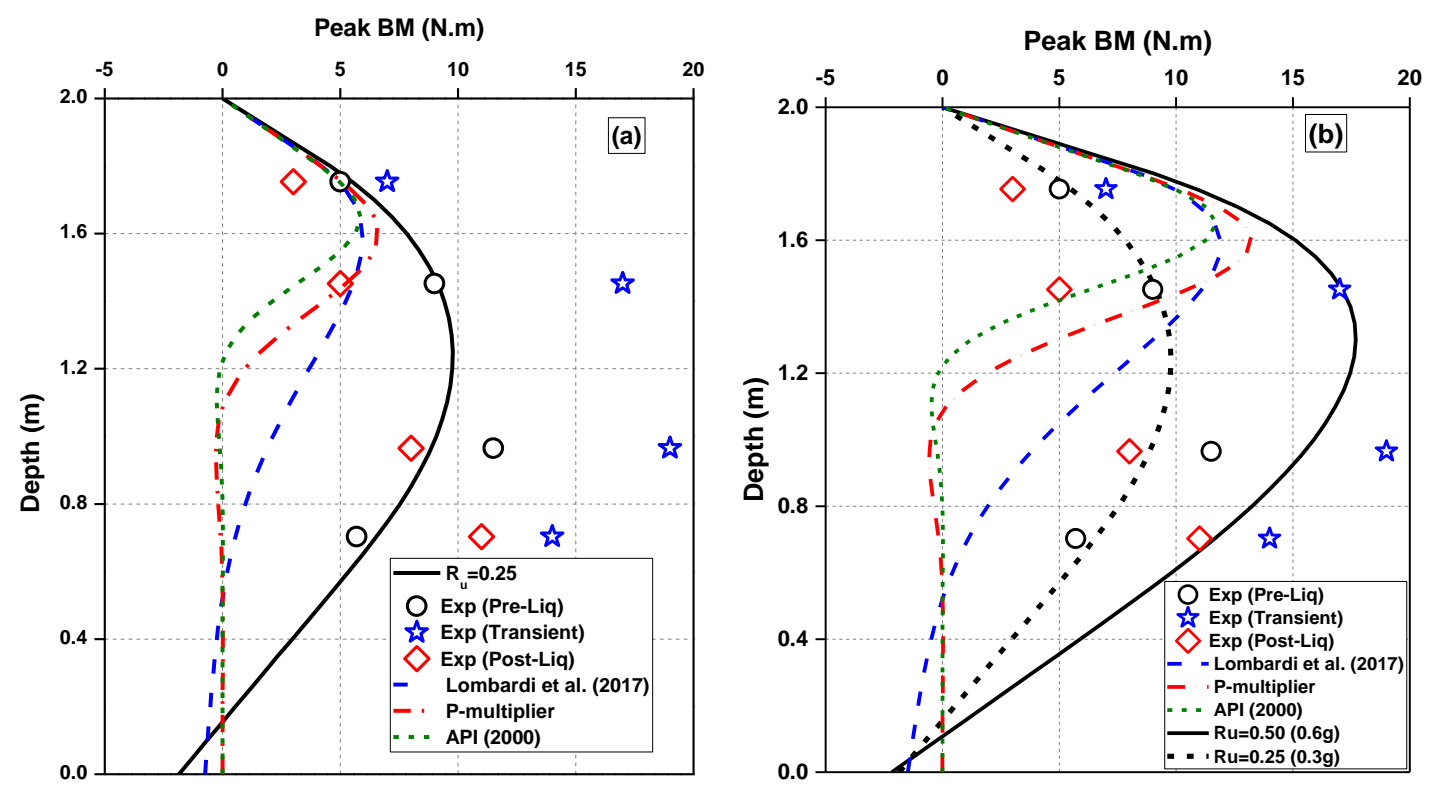

Figure 10. Bending moment profile compared with the proposed partial liquefaction curves at (a) $25 \%$ liquefaction and (b) $50 \%$ liquefaction

It is clear that neither of the traditional approaches could catch the magnitude of the peak $\mathrm{BM}$, while the experimentally derived $25 \%$ and $50 \%$ liquefied P-Y curves show a close match to the shake table results. The trend of the peak BM along the pile depth is also simulated uisng the partial liquefaction models proposed testifying the efficacy of the method. This is due to the strainsoftening and hardening behavior of the partial liquefiable soils which was properly caught in the laboratory element tests. The narrow difference existing for the partially liquefied P-Y curves could possibly due to the dynamic amplification factor as the present analysis is purely based on the pseudo-static analysis without considering the dynamics involved during the liquefaction. The dynamics of the pile supported structures could also play a significant role such as the lengthening of the period and increase in damping period leading to higher response Lombardi \& Bhattacharya, (2014).

\section{CONCLUSION}

A simplified BNWF spring approach for estimating the bending response of pile foundations in partially liquefiable soils is proposed. Multi-stage cyclic triaxial tests are performed on Redhill 110 sand specimens to understand the post-liquefaction behavior of partially liquefiable soils. It is understood that the initial stiffness of the soil reduces with increase in the level of liquefaction and there could possibly exists a threshold liquefaction level beyond which the entire initial stiffness would be lost. The obtained stress-strain response from the element tests are converted to P-Y curves using the scaling coefficients and then used in the numerical model. Pseudo-static analyses were performed to validate the proposed method and the shake table test results of Rouholamin (2016) were considered. It was concluded that the proposed method could satisfactorily catch the 
bending response of pile foundations during partial liquefaction based on the pseudo-static analyses performed.

The dynamics of the problem are not considered in the present work and it is expected that the dynamics influence the pile supported structure's performance during liquefaction. Further work is in progress to fully understand the partial liquefaction behavior of real field soils and include the dynamics along with the hysteretic damping behavior.

\section{REFERENCES}

Amar Bouzid, D., Bhattacharya, S., \& Dash, S. R. (2013). Winkler Springs (p-y curves) for pile design from stress-strain of soils: FE assessment of scaling coefficients using the Mobilized Strength Design concept. Geomechanics and Engineering, 5(5), 379-399. https://doi.org/10.12989/gae.2013.5.5.379

API. (2007). Recommended Practice for Planning, Designing and Constructing Fixed Offshore Platforms - Working Stress Design. Api Recommended Practice, 24-WSD(December 2000), 242. https://doi.org/10.1007/s13398-014-0173-7.2

Bhattacharya, S., Tokimatsu, K., Goda, K., Sarkar, R., Shadlou, M., \& Rouholamin, M. (2014). Collapse of Showa Bridge during 1964 Niigata earthquake: A quantitative reappraisal on the failure mechanisms. Soil Dynamics and Earthquake Engineering, 65, 55-71. https://doi.org/10.1016/j.soildyn.2014.05.004

Brandenberg, S. J. (2005). Behavior of pile foundations in liquefied and laterally spreading ground. $\quad$ Retrieved from http://cgm.engr.ucdavis.edu/Research/projects/pds/BrandenbergDissertation.pdf

Dobry, R., Taboada, V., \& Liu, L. (1995). Centrifuge Modelling of Liquefaction Effects during earthquakes. In 1st Int. Conf. on Earthquake Geotechnical Engineering (pp. 14-16).

Lombardi, D., \& Bhattacharya, S. (2014). Modal analysis of pile-supported structures during seismic liquefaction, (July 2013), 119-138. https://doi.org/10.1002/eqe

Lombardi, D., Bhattacharya, S., Hyodo, M., \& Kaneko, T. (2014). Undrained behaviour of two silica sands and practical implications for modelling SSI in liquefiable soils. Soil Dynamics and Earthquake Engineering, 66, 293-304. https://doi.org/10.1016/j.soildyn.2014.07.010

Lombardi, D., Dash, S. R., Bhattacharya, S., Ibraim, E., Muir Wood, D., \& Taylor, C. A. (2016). Construction of simplified design $p-y$ curves for liquefied soils. Géotechnique, 1(3), 1-12. https://doi.org/10.1680/jgeot.15.P.116

Ministry of Transport Japan (MoT). (1999). Design standard for port and harbour facilities and commentaries.

Rouholamin, M. (2016). An Experimental Investigation Of Transient Dynamics Of Pile-Supported Structures In Liquefiable Soils By Mehdi Rouholamin A thesis submitted for the degree of Doctor of Philosophy at the University of Surrey ,.

Rouholamin, M., Bhattacharya, S., \& Orense, R. P. (2017). Effect of initial relative density on the post-liquefaction behaviour of sand. Soil Dynamics and Earthquake Engineering, 97(September 2016), 25-36. https://doi.org/10.1016/j.soildyn.2017.02.007 